Association for Information Systems

AIS Electronic Library (AISeL)

Fall 11-28-2006

\title{
A Holistic Method for Finding Out Critical Features of Industry Maintenance Services
}

Juha-Matti Ranta

Josu Takala

Follow this and additional works at: https://aisel.aisnet.org/iceb2006

This material is brought to you by the International Conference on Electronic Business (ICEB) at AIS Electronic Library (AISeL). It has been accepted for inclusion in ICEB 2006 Proceedings by an authorized administrator of AIS Electronic Library (AISeL). For more information, please contact elibrary@aisnet.org. 


\title{
A holistic method for finding out critical features of industry maintenance services
}

\author{
Juha-Matti Ranta ${ }^{\mathbf{1}}$, Josu Takala ${ }^{2}$ \\ ${ }^{1}$ post-graduate student, University of Vaasa, juha-matti.ranta@uwasa.fi \\ ${ }^{2}$ professor, University of Vaasa, josu.takala@uwasa.fi
}

\begin{abstract}
The purpose of this case study is to create a competitive operative management system for efficiency and quality performance for a company running maintenance service business for globally competitive forest industry production. Furthermore the research aim is to find out and eliminate obstacles affecting efficiency by identifying the factors that can cause problems in the near future in the service process. This evidently means efforts to create and implement new "eWorld suitable sense and respond" methods to measure, follow and improve performance of the service production. The theoretical framework was drawn up to summarize the major findings about up-to-date topics on industrial production related services having high competence and competitiveness requirements, and to act as a guideline for the empirical pilot research. A qualitative research method with multicriteria decision making process was created and utilised in order to collect data through in-depth expert interviews. The performance measurement and improvement system developed has been piloted in two small scale production maintenance service processes with encouraging experiences, and have already been implemented into everyday use.
\end{abstract}

Keywords - performance management, multicriteria decision making, competitiveness, maintenance, service, process industry, production

\section{INTRODUCTION}

The purpose of this study is to develop a customer questionnaire process by which the customer satisfaction and the critical factors of the certain maintenance service of case-company can be monitored and evaluated. The results of the customer questionnaire process can be utilized furthermore for example in performance measurement systems. Theory of customer questionnaire process is based on Rautiainen`s and Takala`s [11] research. The data regarding a service's current situation was collected through interviews with the case-company's employees.

The case-company, Stora Enso Saimaa Services Oy (SESS), is an internal service company which provides maintenance and other services for Stora Enso Imatra Mills.
SESS currently has about 800 employees and turnover is approximately EUR 70 million per year.

\section{CUSTOMER SATISFACTION AND OPERATIONS STRATEGIES FOR SENSE AND RESPONSE SERVICES}

Quality is often considered one of the keys to success. In fact, according to PIMS (Profit Impact of Market Strategy) data base, including information from manufactures and service firms alike, customer perceived quality is found to be of exceedingly great importance to success. The competitive advantage of a firm depends on the quality of the goods and services provided [4], [17].

Service quality is whatever the customers say it is, and the quality of a service is whatever the customer perceives it to be [4], [5]. For service companies the challenge of customer satisfaction is identifying the critical factors that determine customer satisfaction and customer loyalty [7]. Service quality is the discrepancy between customers' expectations and experience. Good perceived quality is obtained when the experienced quality meets the expectations of the customer, that is, the expected quality. [4], [6], [17].

The several key factors shape customers' expectations: what customers hear from other customers, their personal needs, past experiences and external communications. Price can also be a factor which plays an important role in shaping expectations. Knowing what customers expect is the first and possibly most critical step in delivering quality service. Stated simply, providing services that customers perceive as excellent requires that a firm knows what customers expect. Being a little bit wrong about what customers want can mean losing a customer's business when another company hits the target exactly. Being a little bit wrong can mean expending money, time and other resources on things that don't count on customers. Being a little bit wrong can even mean not surviving in a fiercely competitive market [17].

How we actually can sense customers` needs and how to develop new capabilities to respond their needs more effectively. Revolutionary change in information technology enables companies to use "sense and respond" strategies. Rather than competing by forecasting customers' needs, companies are relying on real-time sensors to 
continuously discover what customer needs and delivering efficiently value to customers. The intention is to understand customers [3]. In addition to expectations and experiences the competitors and direction of development have a great influence to customer satisfaction. By taking also these things into consideration in the customer questionnaire process, the method will be versatile [12].

Service process analysis provides a normative framework in which the efficiency of different service capabilities can be evaluated in a matrix. In analysing the logistic processes and information systems that provide service capabilities, there are two questions to be answered: [8], [14]. How should organisations and services be represented systematically to allow comparisons of different strategies? And, what is the criterion of efficiency for matching services and channels that helps in selecting the best combinations for a company? The main idea of the service process analysis matrix (Fig. 1) is to evaluate the efficiency of matching the type of service offered with alternative types of delivery channels. The axes of the SPA (service process analysis) matrix represent the type of service and type of channel. [8], [14].

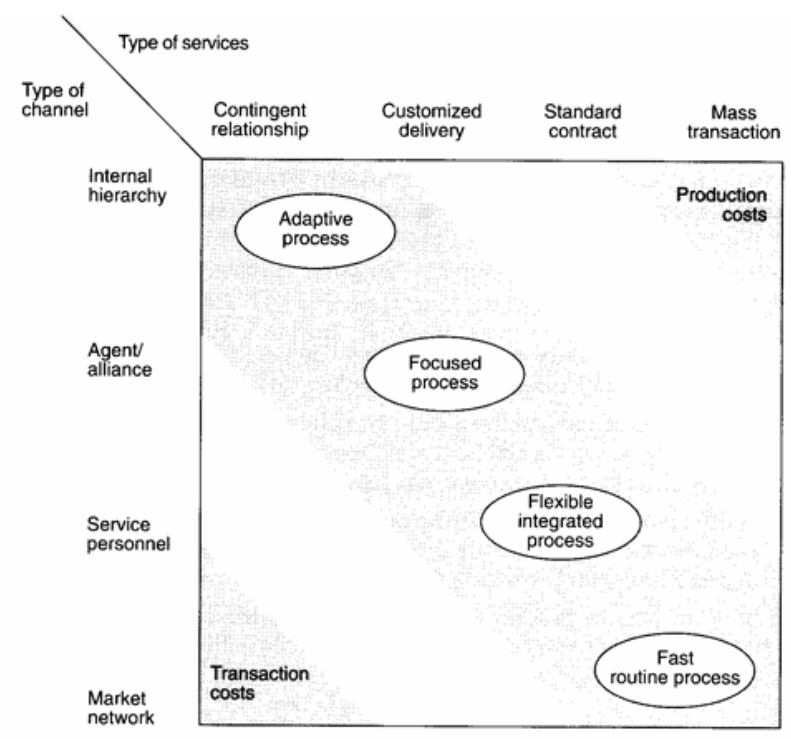

Figure 1. Service Process Analysis matrix [14]

A service process is carried out within a delivery channel that consists of some organisations and the interconnections among them. The channel contains front-line employees and staff members of the service-providing firm. It is important to see customer as a one part of entire service channel and re-examine the justification of current organisational boundaries. We can define four types of services: [8], [14].

- Mass transactions.

- Standard contracts.

- Customised delivery.

- Contingent relationship.

Contingent relationship deals with complex problems and contingencies requiring intensive communication. This type of service is described by risk sharing requiring close relationships. [8], [14]. In cross points of service types and channels we can define also four efficient service processes: [8], [14]

- Fast routine processes.

- Flexible integrated processes

- Focused processes.

- Adaptive processes.

To get best possible advantage in the market and increase value of customers companies has to make right choices both service and channel type. We can define three points to be taken into consideration making right conclusions: What is the company's position right now. What is the desired direction of the company? And, how fast the desired target will be reached?

SESS evidently would like to collaborate by focused processes and customized deliveries with its customer Stora Enso. However, in practice the customer needs all the types of service processes from fast routine processes to adaptive processes from SESS.

\section{BUILDING THE METHOD}

When measuring and evaluating customer satisfaction the first steps is to study the company's service process. The study must be focused to the process operations which produce different attributes of service. The connection between process operations and the attributes of services is really important because attributes arose in operations. In this way it is easier to improve customer satisfaction on the basis of the customer feedback [11]. Fig. 2 emphasizes the importance of the connection.

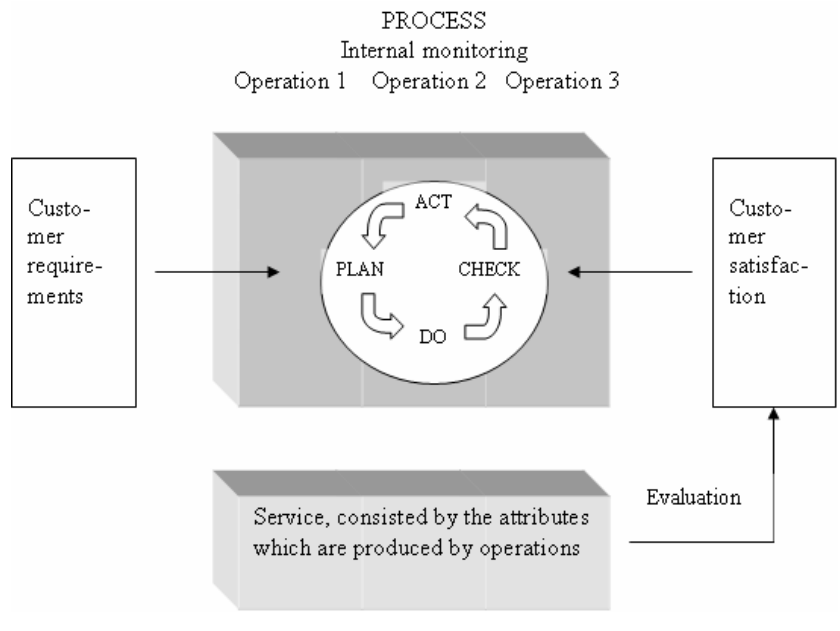

Figure 2. Continuous improvement of customer satisfaction linked to process operations [11]

When the service is divided into operations, each of which produces attributes for the service, it is possible to monitor the improvement of customer satisfaction in both internally and externally. This is a vital thing to achieve improvements. 
After studying the company's service process is possible to establish customer opinions and feelings. In study of Rautiainen \& Takala information collected from customers with questionnaire. It was measured attributes taking customers' expectations and experiences, impressions of competitors and direction of development into account. To remain the reliability and validity high the questionnaire was short, clear and easy to answer. The more comfortable the questionnaire is to answer the more reliable and valid the answer is. And addition to that more answers are given. Rautiainen \& Takala used a simple numerical estimationscale from 1 to 10 . The wide scale makes it easy to find differences between attributes [15]. The questionnaire measures expectations, experiences, performance proportioned to competitors and direction of development [11]. Figure 3 introduces the way how information was gathered.

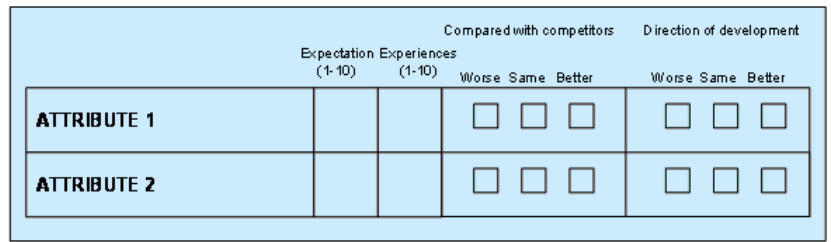

Figure 3. Model of questionnaire [11].

Rautiainen \& Takala analyzed answers so that in the beginning were calculated standard deviations, averages and making some distributions. The standard deviations and averages were calculated on the grounds of evaluations of certain attribute. The distributions were formed of the numbers of the answers compared to all the numbers of the answers [11]. Table 1 introduces an example what the preliminary analysis produced.

Table 1. Preliminary analysis [11].

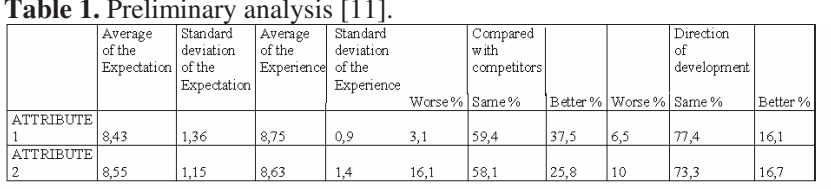

After preliminary analysis Rautiainen \& Takala used three different tools to identify the most important development subjects of the service. All the tools used the numbers and distributions which were calculated during the preliminary analysis [11]. Gap analysis was used to compare differences between customers' expectations and experiences. With this basic tool can identify those attributes where the experiences were more insignificant than expectations. This kind of attributes can be chosen for development subjects. Nevertheless if too many attributes has gap between experiences and expectations, more tools have to be utilized [11]. Implementation index (IMPL) measures importance and pressure to improve. To increase the sensitivity of the deviation in competitive priorities the standard deviation has been developed into implementation index by dividing the standard deviation by the value of corresponding competitive priority (importance) in order to improve the possibility to compare different attributes with each other. The smaller value is the bigger possibility to develop [13]. Emphasized Implementation Index measures also importance and pressure to improve. As noted above competitors and direction of development have also an effect on customer satisfaction and customer loyalty. This IMPL is emphasized by the competitor index and the direction of development index. The implementation index uses distributions which are counted from the answers which applied competitors and direction of development. The smaller value is the bigger need to improve the attribute [11]. Equations are showed in Figure 4.

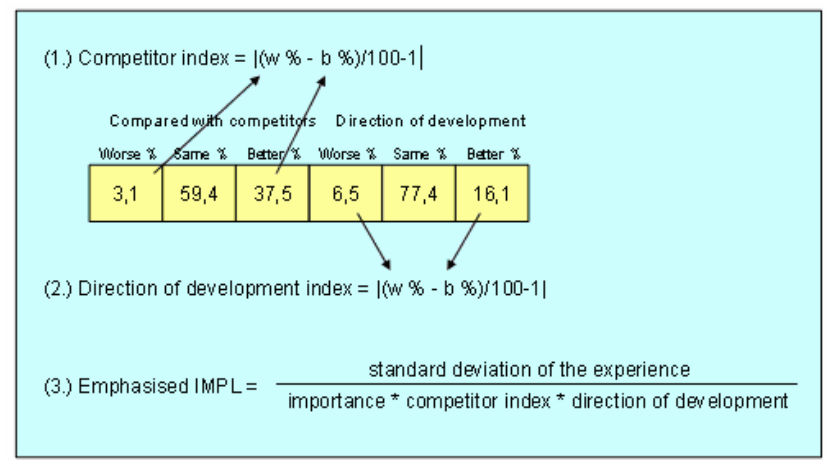

Figure 4. Equations [11].

Developed customer questionnaire process bases on study of Rautiainen and Takala [11]. Some parts and analyzing methods have been added and modified for this case. Developed customer questionnaire process is a 3-phase method:

1. Phase: Current State Analysis.

Tools: Personnel interviews, in-depth interviews, observing.

2. Phase: Identify factors and attributes which affect quality and success of service. Questions have to be in line with strategy of the company so that all the customer groups are represented in the right proportions.

Tools: Information from the first phase, business process descriptions, service descriptions. The company's vision, mission, -values, -strategy.

3. Phase: Analysis of the questionnaire, observations and conclusions.

Tools: Customer questionnaire results analyzing tools.

As Rautiainen and Takala noted, first step is get acquainted to the company's service process. This can happen with interviews and observing. After this it is possible to move on the second phase and build the questionnaire. In third phase the results will be analysed and after that it is possible to make conclusions. The preliminary analysis was produced just as in study of Rautiainen and Takala. If too many attributes have gaps between experiences and expectations more analyzing tools will be needed. The main goal is to find critical factors of service. Emphasized implementation index is a workable tool for this purpose, but it requires that customers can compare case-company to competitors. However, we assume that the customers of 
case-company can't do this kind of comparing because in practice the case-company is the only service provider and that's why new analyzing tool will be needed.

Direction of development index of Rautiainen and Takala formed for this new analyzing tool so that variables of separation change the place among. Moreover results of gap analysis and importance of attributes formed such form that using of those come possible. In this case importance of attribute is same as average of expectations because customers have long-term experiences of the casecompany's services and customers process is established. Gap index, Direction of development index and Importance index are introduced in Figure 5.

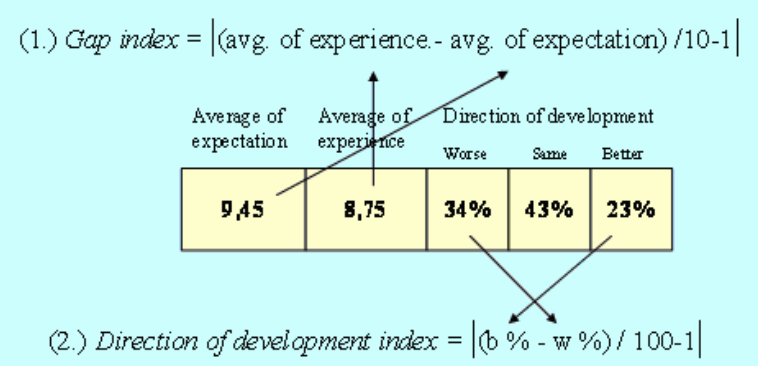

(3.) Importance index $=$ avg. of expectation $/ 10$

Figure 5. New equations.

Value 1 in Direction of development index means that performance has remained on the same level. Value under 1 means that it has developed and over 1 means that it has decreased. Respectively in Gap index value 1 means that there is no gap, value over 1 means that experiences are lower than expectations and value under 1 means conversely. In Importance index the bigger value means a more important expectation of the attribute.

Critical factors index (CFI) was developed for the casecompany. By this tool it is possible to find out critical factors of the service. The smaller value corresponds to a more critical factor.

$$
\text { CFI }=\frac{\text { standard deviation of expectation } * \text { standard deviation of experience }}{\text { Importance index } * \text { Gap index } * \text { Direction of development index }}
$$

CFI is a more comprehensive and practical method than Emphasized Implementation Index because it observes also standard deviation of expectations and gap between customer experiences and expectations. In addition to it is possible to add Competitor index to denominator of CFI if determination of Competitor index is possible. Results of Critical factors index can be multiplied by 10 or 100 to make it easier to monitor the values.

\section{RESULTS}

The developed customer questionnaire process was tested in the case-company. It was carried out for a certain maintenance service. Firstly the researchers learned the service's features and current state with interviews and observing. After this the researchers and service providers established the questionnaire. 20 attributes were measured taking customers' expectations and experiences, impressions of competitors and direction of development into account. The period under review in direction of development section was two years because the casecompany's maintenance services had re-organized one and a half year ago. Compared with competitors section was in questionnaire first for testing purposes because we assumed that the customers of the case-company could not do this kind of comparing. The quantitative analysis of the results compared with the competitors wasn't possible. The customers were requested to evaluate among others: professional skills of service makers, service minded of service makers, timing of service, price-quality ratio of service and how well service makers take care of safety and environmental factors, see Appendix A.

The respondents were selected so that all the customer groups would be represented uniformly. Questionnaire delivered for 31 customer and 17 of them answered (55\%). On the basis of the response rate, the questionnaire implemented seems to be very successful because the response rate of earlier customer questionnaire in casecompany has been only about $35 \%$. Our questionnaire was delivered personally to the customers and this might have positive influence to the response rate. Table 2 shows the preliminary results analysed by the methods introduced in this study.

\begin{tabular}{|c|c|c|c|c|c|c|c|}
\hline & \multirow{2}{*}{\begin{tabular}{|l|}
$\begin{array}{l}\text { Average } \\
\text { of the } \\
\text { Expectation }\end{array}$ \\
\end{tabular}} & \multirow{3}{*}{$\begin{array}{l}\begin{array}{l}\text { Standard } \\
\text { deviation } \\
\text { of the } \\
\text { Expectation }\end{array} \\
0.61\end{array}$} & \multirow{2}{*}{$\begin{array}{l}\begin{array}{l}\text { Average } \\
\text { of the } \\
\text { Experiences }\end{array} \\
89\end{array}$} & \multirow{2}{*}{$\begin{array}{l}\text { Standard } \\
\text { Deviation } \\
\text { of the } \\
\text { Experiences }\end{array}$} & \multicolumn{3}{|c|}{ Direc tion of development } \\
\hline & & & & & Worse \% & Same \% & Better \% \\
\hline ATTRBOTE 1 & $\mid 9,65$ & & & 1,38 & 12,50 & 68,75 & 18,75 \\
\hline ATTRIBUTE 2 & 9,47 & 0,87 & 9,12 & 0,86 & 0,00 & 87,50 & 12,50 \\
\hline ATTRBUTE 3 & 9,24 & 0,75 & 8,59 & 0,71 & 0,00 & 80,00 & 20,00 \\
\hline ATTRBUTE 4 & $\underline{8.53}$ & 1,12 & 8,29 & 1,05 & 0,00 & 73,33 & 26,67 \\
\hline ATTRB UTE 5 & 9,53 & 0,80 & 7,82 & 1,07 & 25,00 & 68,75 & 6,25 \\
\hline ATTRBUTE 6 & 9,38 & 0,81 & 7,88 & 1,09 & 21,43 & 64,29 & 14,29 \\
\hline ATTRBUTE 7 & 9,24 & 0,97 & 8,53 & 1,12 & 0,00 & 100,00 & 0,00 \\
\hline ATTRBUTE 8 & 9,29 & 0,77 & 8,53 & 0,80 & 0,00 & 100,00 & 0,00 \\
\hline ATTRBUTE 9 & 9,38 & 0,72 & 8,50 & 0,97 & 7,14 & 85,71 & 7,14 \\
\hline ATTRIBUTE 10 & 9,47 & 0,80 & 8,65 & 0,86 & 0,00 & 86,67 & 13,33 \\
\hline ATTRIBUTE 11 & 9,18 & 1,01 & 8,65 & 1,37 & 0,00 & 86,67 & 13,33 \\
\hline ATTRIBUTE 12 & 9,56 & 0,81 & 8,06 & 1.77 & 7,14 & 78,57 & 14,29 \\
\hline ATTRIBUTE 13 & 9,29 & 0,85 & 7.76 & 1,44 & 0,00 & 92,86 & 7,14 \\
\hline ATTRIBUTE 14 & 9,00 & 1,13 & 7.33 & 2.06 & 0,00 & 37,50 & 62,50 \\
\hline ATTRIBUTE 15 & 8,40 & 1,52 & 6,20 & 2,49 & 33,33 & 33,33 & 33,33 \\
\hline ATTRIBUTE 16 & 8,94 & 1,20 & 8,12 & 1,11 & 7,14 & 78,57 & 14,29 \\
\hline ATTRIBUTE 17 & 9,56 & 0,89 & 8,81 & 0,66 & 0,00 & 92,86 & 7,14 \\
\hline ATTRIBUTE 18 & 9,25 & 0,88 & 8,38 & 1,26 & 0,00 & 92,86 & 7,14 \\
\hline ATTRIBUTE 19 & 9,50 & $\underline{1,20}$ & 7,88 & 1,36 & 12,50 & 62,50 & 25,00 \\
\hline ATTRIBUTE 20 & 9,17 & 0,98 & 7,83 & 1,17 & 0,00 & 83,33 & 16,67 \\
\hline
\end{tabular}

In the preliminary analysis it is worth of noticing the high values of expectations and also that every attribute has gap between experiences and expectations. Because of the many gaps more analyzing tools had to be utilized. Direction of development index was determined next. Gap index was also determined for Critical factors index (CFI); see Tables 3 and 4, and Figure 6.

Table 3. Direction of development index and Gap index. 


\begin{tabular}{|ll|l|}
\hline & $\begin{array}{l}\text { Direction of } \\
\text { development index }\end{array}$ & Gap index \\
ATTRIBUTE 1 & 0,94 & 1,08 \\
ATTRIBUTE 2 & 0,88 & $\mathbf{1 , 0 4}$ \\
ATTRIBUTE 3 & 0,8 & 1,06 \\
ATTRIBUTE 4 & $\mathbf{0 , 7 3}$ & $\mathbf{1 , 0 2}$ \\
ATTRIBUTE 5 & 1,19 & 1,17 \\
ATTRIBUTE 6 & $\mathbf{1 , 0 7}$ & 1,15 \\
ATTRIBUTE 7 & 1 & 1,07 \\
ATTRIBUTE 8 & 1 & 1,08 \\
ATTRIBUTE 9 & 1 & 1,09 \\
ATTRIBUTE 10 & 0,87 & 1,08 \\
ATTRIBUTE 1 & 0,87 & $\mathbf{1 , 0 5}$ \\
ATTRIBUTE 12 & 0,93 & 1,15 \\
ATTRIBUTE 13 & 0,93 & 1,15 \\
ATTRIBUTE 14 & $\mathbf{0 , 3 8}$ & $\mathbf{1 , 1 7}$ \\
ATTRIBUTE 15 & 1 & 1,22 \\
ATTRIBUTE 16 & 0,93 & 1,08 \\
ATTRIBUTE 17 & 0,93 & 1,08 \\
ATTRIBUTE 18 & 0,93 & 1,09 \\
ATTRIBUTE 19 & 0,88 & 1,16 \\
ATTRIBUTE 20 & 0,83 & 1,13 \\
\hline
\end{tabular}

Only two performance attributes had deteriorated on the basis of Direction of development index (Attributes 5 and 6 ). Other performance attributes had remained on same level or improved. Especially noteworthy is remarkably positive development of Attribute 14 because recently the case-company had put efforts for developing of it.

The research objective was to find out and identify service strengths and weaknesses and above all the most critical factors of the service. Finally, these aims was tried to be achieved by Critical factors index.

Table 4. Results of Critical factors index.

\begin{tabular}{|l|l|l|l|}
\hline \hline ATTRIBUTE 1 & 0,86 & ATTRIBUTE 11 & 1,65 \\
\hline ATTRIBUTE 2 & 0,86 & ATTRIBUTE 12 & 1,40 \\
\hline ATTRIBUTE 3 & $\mathbf{0 , 6 8}$ & ATTRIBUTE 13 & 1,23 \\
\hline ATTRIBUTE 4 & 1,85 & ATTRIBUTE 14 & 5,82 \\
ATTRIBUTE 5 & $\mathbf{0 , 6 5}$ & ATTRIBUTE 15 & 3,69 \\
ATTRIBUTE 6 & 0,76 & ATTRIBUTE 16 & 1,49 \\
ATTRIBUTE 7 & 1,10 & ATTRIBUTE 17 & $\mathbf{0 , 6 1}$ \\
\hline ATTRIBUTE 8 & $\mathbf{0 , 6 1}$ & ATTRIBUTE 18 & 1,18 \\
\hline ATTRIBUTE 9 & $\mathbf{0 , 6 8}$ & ATTRIBUTE 19 & 1,68 \\
\hline ATTRIBUTE 10 & 0,78 & ATTRIBUTE 20 & 1,33 \\
\hline
\end{tabular}

With Critical factors index (CFI) the most critical factors of service were identified (Attributes 3, 5, 8, 9 and 17). So, attention has to be paid e.g. to professional skills of service makers, timing of service, efficiency of service's completion and how well service providers take care of safety.

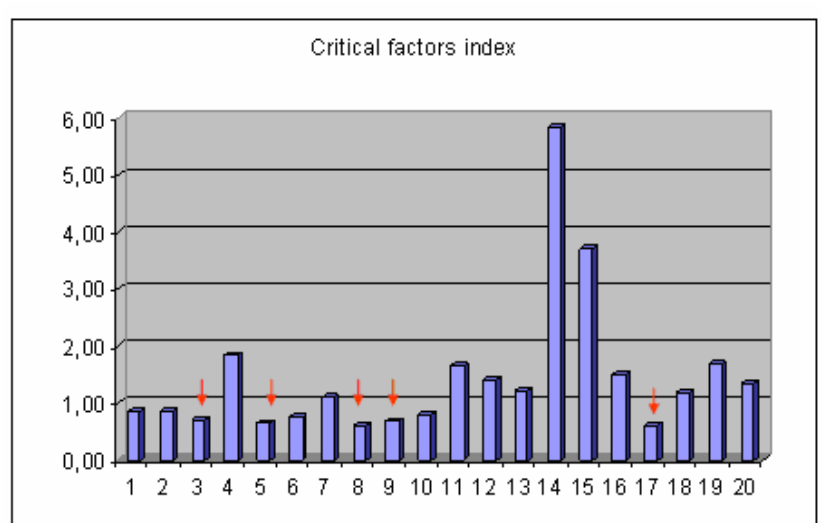

Figure 6. Results of Critical factors index.

\section{UTILIZATION AND EVALUATION OF THE RESULTS}

Within this case study research, a constructive method for finding out critical features of industry maintenance services was developed and tested by weak market test. The method helped the company to identify the strengths, weaknesses and critical factors of the service. This identifying based on recognition of service attributes, clarification of customers opinions and systematic analysis of these gathered information. The standard deviations, Critical factors index and the weak market test verified the validity and the reliability of this survey.

Current state analysis, customer questionnaire and analysis of it succeeded according to targets. With thorough current state analysis all essential questions for questionnaire was founded. After this questionnaire was delivered for all customer groups and answers were received enough for analysis.

With analysis was observed that customers expect extremely high level of service performance. It was also observed that every attribute has gap between experiences and expectations and that's why more analysis tools were needed. With Direction of development index it was find out what attributes have developed and which had deteriorated. This is really important information because for example it indicates that customers have noticed the development activity of the case-company.

With Critical factors index the most important attributes were identified. On the basis of the index attention has to be paid especially to professional skills of service providers, timing of service, efficiency of service's completion and how well service providers take care of safety. However low value of Critical factors index doesn't necessarily mean that the performance of the attribute is on a low level. Low value of the index can also be courtesy of customer unanimous opinions about expectations and experiences. That's why it's really important that results of customer questionnaire process will be evaluated holistically. In that case it's possible to plan and implement the right further actions: intensive improving or deliberate improving. 
Results of the customer questionnaire process have to be examined in depth with service providers. The results are a highly qualified feedback of the service. And that's why it's extremely valuable information for the service providers.

In the case-company information and results of the customer questionnaire process was utilized also in developing process of measurement system in work group level. Customer questionnaire process gave valuable information about customer opinions and results of Critical factors index showing directly which attributes have to be measured. Consequently customer questionnaire process was associated to developing process of measurement system.

Experiences from the customer questionnaire process are still preliminary. However, some general conclusions and conclusions about just this individual customer questionnaire process be proposed.

In this study customer questionnaire process gave important information from the service examined. With it strengths, weaknesses and critical factors of the service were identified. This all based on customer satisfaction survey. With this process it's also possible to take into account opportunities and threats of the service but this requires that customers can compare case-company's service to competitors. In that case Competitor index may add on to denominator of Critical factors index. Customer questionnaire process was also significant part of developing process of measurement systems. Overall customer satisfaction measurements, analyses and proposals for actions can be systemized by using the method developed.

Highly reliable evaluations aren't possible until the method has utilized few years in case-company. Customer questionnaire process have to be repeated couple of times and in this way it will be possible to find out if it is possible to recognize changes of internal and external business environment with this method. Especially the method should sense changes in the attribute criticality. Besides, it should be able to discover that what causes these criticality changes: customer expectations, development of internal factors, deterioration of internal factors, competitive environment.

\section{FURTHER DEVELOPMENTS AND MANAGERIAL IMPLICATIONS}

Because we always have to focus to a small amount, let's say e.g. to 4 , of priorities in even multifocused business strategies, that the business strategy is under reliable control. Some actions have already been carried out and some are under implementation in the case business. In a long run the effects can not yet be considered. And what might be the "higher level" performance measurements for that? Should we use productivity, profitability, market shares or growth rates of the business? In the long run we have to repeat the customer satisfaction measurement and development actions to follow and make some conclusions from the effects to the higher level business performance. This is a challenge in a dynamic and complex service business where e.g. the amount of reclamations does not necessarily mean anything in customer satisfaction. Therefore, we can conclude that there is still a tremendous need for developing a simple and holistic customer satisfaction measurement and a higher level business performance measurement related to it. What might this mean in practice?

We have to always first find out the priorities of the customer satisfaction for the dynamic business conditions, and secondly and based to that performance pyramid, to follow the micro mechanism how this affects the higher level business performance. This is really a continuous research and development process when keeping the service business competitive. The holistic customer satisfaction system is all the time changing; some arguments are going up and some down. This fact may cause serious problems because the flexibility, i.e. the life cycle of the customer satisfaction arguments should high be enough, to prevent us from taking all the time new dimensions in the customer satisfaction measurement. Therefore, when searching for a quality information system we should really be very careful just to have the right, that is flexible (long life cycle) enough, customer satisfaction arguments, to make sure continuous and reliable business development. This fact evidently requires dynamic, hermeneutic and for the mostly qualitative studies, to all the time ensure the right understanding of the customer quality behaviour and its effects to business management. This case study illustrates difficulties and problems in decision making especially in huge companies. For example service operations can't be categorised unambiguously in ServiceChannel matrix because service operates quite widely in almost all the service types. In some cases this might look like chaos but closer look illustrates that it is only a way to keep customer satisfied in this special business area [14]. These Service Process Analyses obviously mean great challenges for the further developments of the maintenance service.

\section{REFERENCES}

[1] Bask, Anu H (2001). Relationships among TPL providers and Members of Supply chains - a strategic perspective. The Journal of Business \& Industrial Marketing 16:6, 470-486.

[2] Botten, Neil \& John McManus (1999). Competitive Strategies for Service Organisation. London: Macmillan Press LTD. 327.

[3] Bradley, Stephen P. \& Richard L. Nolan (1998). Sense \& Respond Capturing Value in the Network Era. Harvard Business School Press. Boston, Massachusetts.

[4] Grönroos, C. 1990. Service Management and Marketing, Managing the moments of Truth in Service Competition. Toronto, Massachusetts: Lexington Books.

[5] Grönroos, C. 1998. Nyt kilpaillaan palveluilla. 4. Edition. Porvoo: WSOY.

[6] Grönroos, C. 2001. Palveluiden johtaminen ja markkinointi. Porvoo: WS Bookwell.

[7] McDougal, Gordon H.G. \& Terrence Levesque (2000). Customer satisfaction with services: putting perceived value into the equation. Journal of Services Marketing Vol. 14 No. 5, pp.392-410 
[8] Jahnukainen, Miika \& Ari P.J. Vepsäläinen (1992). Joining the Global Race. Helsinki: Helsinki School of Economics.162.

[9] Jerome, Laurie \& Brian H. Kleiner (1995). Employee morale and its impact on service: what companies do to create a positive service experience? Managing Service Quality 05:6, 21-2

[10] Parasuraman, A., Zeithaml, Valerie A. \&Berry, Leonard, L. (1985) A Conceptual Model of Service Quality and Its Implications for Future Research. Journal of Marketing, 1985, Vol. 49, No. 4, pp. 41-50.

[11] Rautiainen, M. \& Takala, J (2003). Measuring Customer Satisfaction and Increasing it by Choosing the Right Development Subjects. LOADO'2003, High Tatras, Slovakia. Stora Enso Intranet. [cited 14.7.2006].

[12] Strauss, Bernd \& Patricia Neuhauss (1997). The qualitative satisfaction model. International Journal of Service Industry Management Vol. 8 No. 3, pp.236-249

[13] Takala, Josu (2002). Analysing and Synthesising Multifocused Manufacturing Strategies by Analytical Hierarchy Process, International Journal of Manufacturing Technology and Management, Vol.4, No.5, 2002, pp. 345-350.

[14] Tinnilä, Markku \& Ari P.J. Vepsäläinen (1995). A model for strategic repositioning of service processes. International Journal of Service Industry Management 06:4, 57-80.

[15] Vavra, Terry G. (1997). Improving Your Measurement of Customer Satisfaction. Milwaukee: ASQ Quality Press.

[16] Woodruff, Robert B. \& Sarah Fisher Gardial (1996). Know your Customer: New Approaches to Understanding Customer Value and Satisfaction. Cambridge: Blackwell Publishers.
[17] Zeithaml, Valerie A \& A. Parasuraman \& Leonard L. Berry (1990). Delivering Quality Service. New York: A Division of Macmillan Inc. 226. 


\section{APPENDIX}

Customer questionnaire

Expectations Experiences Compared with competitors Direction of development (1-10) (1-10) Worse Same Better Worse Same Better

X.) Quickness of service.

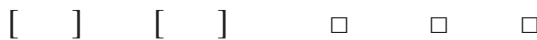

X.) Professional skills of workers.

$\left[\begin{array}{lllll}2 & {[}\end{array}\right] \quad \square \quad \square \quad \square$

X.) Professional skills of foremen.

$\left[\begin{array}{lllll}{[} & {[}\end{array}\right] \quad \square \quad \square \quad \square$

X.) Timing of service.

X.) Accessibility.

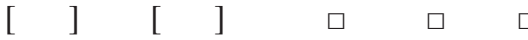

X.) Efficiency of service's completion.

[ ] [

X.) Service makers take care about safety.

[ ] [

X.) Service makers take care about environmental factors.

[ ] [ ]

X.) Service makers take care about tidiness of working environment.

X.) Price/quality ratio of service.

$\left[\begin{array}{ll}1 & {[}\end{array}\right]$

X.) Service minded of workers.

[ ] [ ] $\quad \square \quad \square \quad \square$

X.) Service minded of foreman.

$\left[\begin{array}{lllll}2 & {[}\end{array}\right] \quad \square \quad \square \quad \square$

X.) Reliability of service.

[ ] [

X.) Service providers understand the needs of customer.

X.) Internal cooperation of service providers working.

$\left[\begin{array}{llll}{[} & {[}\end{array}\right] \quad \square$

$X$.) Service providers inform customer during the service. [

X.) Correctness of billing.

$\left[\begin{array}{lll}{[} & ] & {[} \\ {[} & ] & {[}\end{array}\right.$

]

X.) Service providers of area A can operate in area B.

X.) Service providers of area B can operate in area A.

X.) Prioritization ability of foreman.

]

] $\square \quad \square \quad \square$

$\square \quad \square \quad \square$

$\square \quad \square \quad \square$

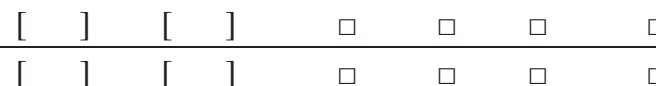

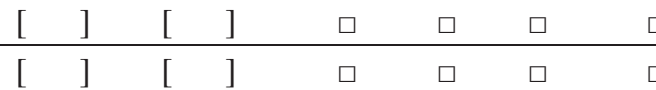

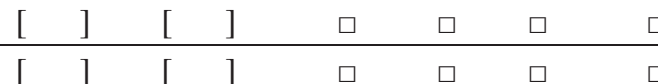

$\square \quad \square$

$\square \quad \square \quad \square$

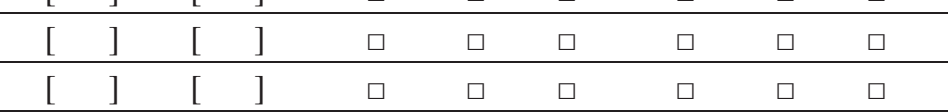

